June 1992

\title{
Personality Disorder and the Recurrent Swallowing of Foreign Bodies
}

Robert Jay Claire, M.D.

Cedars-Sinai Medical Center, Los Angeles, California

Follow this and additional works at: https://jdc.jefferson.edu/jeffjpsychiatry

Part of the Psychiatry Commons

Let us know how access to this document benefits you

\section{Recommended Citation}

Claire, M.D., Robert Jay (1992) "Personality Disorder and the Recurrent Swallowing of Foreign Bodies," Jefferson Journal of Psychiatry. Vol. 10 : Iss. 2 , Article 11.

DOI: https://doi.org/10.29046/JJP.010.2.014

Available at: https://jdc.jefferson.edu/jeffjpsychiatry/vol10/iss2/11

This Article is brought to you for free and open access by the Jefferson Digital Commons. The Jefferson Digital Commons is a service of Thomas Jefferson University's Center for Teaching and Learning (CTL). The Commons is a showcase for Jefferson books and journals, peer-reviewed scholarly publications, unique historical collections from the University archives, and teaching tools. The Jefferson Digital Commons allows researchers and interested readers anywhere in the world to learn about and keep up to date with Jefferson scholarship. This article has been accepted for inclusion in Jefferson Journal of Psychiatry by an authorized administrator of the Jefferson Digital Commons. For more information, please contact: JeffersonDigitalCommons@jefferson.edu. 


\section{Brief Report}

\section{Personality Disorder and the Recurrent Swallowing of Foreign Bodies}

Psychiatrists are frequently asked to assist colleagues with the medical and surgical sequela of psychiatric disorders. The Consultation and Liaison Psychiatry service was consulted by the Surgical Service to evaluate a patient who repeatedly swallowed foreign bodies. The following is a case report, brief review of the literature and discussion.

\section{CASE REPORT}

Patient A. is a 38 year old white male who was admitted to the surgical service after swallowing a nail clipper. His chief complaint was "I guess the surgeons asked you to see me because of poor judgment."

Patient A. admitted to swallowing a watch and a nail clipper within a four month period, describing these gestures as a cry for help. When asked what type of help he stated "a place to live and some money." Although he claimed to be depressed, Patient A. only acknowledged slight sleep disturbance and denied problems with appetite, personal hygiene, concentration or suicidality.

Patient A. impulsively moved from Florida to California one year before this hospital admission. When he arrived in California he had neither a job nor a place to live; he subsequently became overwhelmed by his lack of resources and was frightened. He then spent six months in a "Homeless Vets Program" and was discharged without an Axis I diagnosis or indication for any psychotropic medication.

Patient A. denied any previous psychiatric hospitalization. There was no history of a Major Affective or Thought Disorder. He admitted to alcohol abuse but denied blackouts or delirium tremens. Patient A. admitted to being in a motor vehicle accident and sustaining closed head trauma five years before his current problems began. Since then he reports taking Tegretol 200 mg. twice daily for "Grand Mal Seizures"; however he is unable to describe any details of these seizures and in fact had several normal post-traumatic EEG's.

Patient A. revealed a history of appendectomy, cholecystectomy, multiple exploratory laparotomies and a gastrotomy for removal of a foreign body. It is notable that almost all of these surgeries were complicated by infection.

Patient A. stated that he had been married twice, both ending in divorce and that he was childless. Educationally, he claimed to have a four year college degree. The patient admitted to two arrests, one for loitering and the other for embezzlement.

On mental status examination, Patient A. was a 38 year old white male in hospital pajamas with an intravenous running in his forearm. He was oriented to time, place and person. Speech was of a normal rate, tone, and content. Patient A. reported his mood as depressed and his affect was mood-incongruent with frequent smiling and laughing. Patient A. denied any auditory, visual, or tactile, hallucinations. There was no evidence of suicidality, 
homicidality, ideas of reference, thought broadcasting, insertion or removal. Patient A. had no evidence of impaired short, intermediate or long term memory. Both insight and judgment were impaired, with pronounced impulsivity with lack of regard to consequence.

A meeting was held with the surgical and nursing staff directly involved with Patient A.'s care. It was explained that firm limits and boundaries had to be established, especially with drug seeking types of behavior. I discussed with the staff how unstable personalities are best treated on an outpatient basis, since psychiatric hospitalization tends to make this type even more regressed and primitive. An outpatient mental hygiene clinic referral and lists of homeless shelters were given to Patient A. This patient was discharged from the hospital within forty eight hours without further surgical or psychiatric intervention.

\section{IMPRESSION}

Patient A. did not fit DSM-III R criteria for Major Affective or Thought Disorder. There was a history of alcohol abuse, and in view of his drug seeking behavior, there was at least a suspicion of mixed substance abuse. Patient A. exhibited borderline, histrionic, narcissistic, and avoidant personality traits.

He reported chronic feelings of emptiness, loneliness and boredom as well as a history of impulsivity and high risk behavior. Patient A. tended to see things as absolutes, feeling that you were either his best friend or his enemy. Patient A. had a pattern of constantly seeking approval and praise. He presented a pattern of feeling unhappy when he was not the center of attention and frequently exhibiting sexually seductive behavior. Patient A. had a grandiose image of himself feeling that only special people could understand him. Subsequently the staff who dealt with Patient A. felt personally exploited. Avoidant traits included being easily hurt by criticism and exaggerating potential difficulties in his out of hospital routine.

There is no diagnostic category for recurrent swallowing of foreign bodies in a non-psychotic patient. This symptom complex is most closely related to Factitious Disorder with Physical Symptoms. Patient A.'s recurrent wound infections at least make it appropriate to explore if they were self induced.

\section{DISCUSSION}

A review of the literature on adults swallowing foreign bodies was performed for a ten year period. The most common swallowing of foreign bodies were accidental swallowing of dental appliances. In 1982 James and Allen-Mersh reviewed five cases of recurrent swallowing of foreign bodies, and noted a syndrome of personality disorder, drug abuse or overdose, and self inflicted injuries in three of five patients. They recommend conservative treatment and cautioned against surgical intervention (1).

This phenomenon of recurrent swallowing of foreign bodies did not appear in the psychiatric literature until it was described by Karp, Whitman and Convit in 1991. They report a series of nineteen prisoners who swallowed foreign bodies. The most common motive of swallowing was suicidal ideation with command hallucinations reported by ten patients. In the above series no patient had swallowed a foreign body 
prior to imprisonment (2). They do not explore the relationship of recurrent swallowing of foreign bodies, personality disorder, substance, abuse and self inflicted injury.

My purpose in writing this article is to alert psychiatrists to this syndrome and to urge our medical and surgical colleagues to conservative management.

The opinions presented in this paper are soley those of the author and should not be construed as the views of U.C. Davis or the Department of Veterans Affairs.

\section{ACKNOWLEDGMENT}

I would like to thank: Mark E. Servis, M.D., Chief of the Consultation and Liaison Service for his editorial assistance and Helen Corbett, M.D., Resident in Surgery at the Highland Hospital, Oakland, California for her assistance.

Robert Jay Claire, M.D.

Chief Resident in Psychiatry

Deborah S. Claire, R.N., B.S.N.

Research Coordinator

VA Medical Center

Martinez, CA

\section{REFERENCES}

1. James AH, Allen-Mersh TG: Recognition and management of patients who repeatedly swallow foreign bodies; Journal of the Royal Society of Medicine 1982; 75:107-1 10

2. Karp JG, Whitman L, Convit A: Intenational Ingestion of Foreign Objects by Male Prison Inmates. Hospital and Community Psychiatry 1991; 42(5):533-35 